\title{
A national survey of nurses who care for people with intellectual and developmental disability
}

\author{
AUTHORS \\ NATHAN J WILSON PhD ${ }^{1}$ \\ JAMES COLLISON PhD M. Psych (Clin) ${ }^{2}$ \\ SARAH J FEIGHAN B.Ed. (Early Childhood), BN (Adv) ${ }^{1}$ \\ VIRGINIA HOWIE RN MCN-cardiac PhD (Cand.) ${ }^{3}$ \\ LISA WHITEHEAD PhD ${ }^{4}$ \\ MICHELE WIESE PhD² \\ KATE O'REILLY BN, M.Clin.Research, PhD (Cand.) ${ }^{1}$ \\ HAYDEN JAQUES BN (Adv) ${ }^{1}$ \\ PETER LEWIS PhD ${ }^{1}$
}

1 School of Nursing and Midwifery, Western Sydney University, New South Wales, Australia.

2 School of Social Sciences and Psychology, Western Sydney University, New South Wales, Australia.

3 School of Nursing, Midwifery \& Social Sciences, Central Queensland University, Queensland, Australia.

4 School of Nursing and Midwifery, Edith Cowan University, Western Australia, Australia.

\section{CORRESPONDING AUTHORS}

NATHAN J WILSON School of Nursing and Midwifery, Western Sydney University, Locked Bag 1797, Penrith, NSW, Australia 2751. Phone: +6124570 1926. Email: N.Wilson@westernsydney.edu.au

PETER LEWIS School of Nursing and Midwifery, Western Sydney University, Locked Bag 1797, Penrith, NSW, Australia 2751. Phone: +61 24570 1352. Email: P.Lewis@westernsydney.edu.au

\section{ABSTRACT}

Objective: To describe the roles that Australian nurses play, the breadth of skills that they deploy, and the range of contexts in which they practice.

Study design and methods: This cross-sectional study used a descriptive survey where data were collected online using Qualtrics@ $\subset$. Survey respondents were nurses whose primary role was caring for people with intellectual and developmental disability. In addition to demographic data, the main outcome measures were: nursing roles, practice and context.

Results: Complete responses were collected from 101 nurses; 78 females and 22 males completed the survey, the majority of whom $(n=70)$ were from New South Wales. The major focus of care was direct assessment and care, followed by supervision of support workers, education, and advocacy for people with intellectual and developmental disability. Physical healthcare was consistent across body systems, as it was for all adaptive behaviour domains. Support for mental illness was more likely to be for depression and anxiety. Nurses liaise with a multitude of health and social agencies as part of their nursing practice.

Discussion: This is the first study to capture the roles, practice and contexts of these Australian nurses. Nurses caring for people with IDD play a variety of roles and engage in a vast array of practice related to the physical and social needs of people with intellectual and developmental disability across the whole of the lifespan and in multiple, disparate contexts.

Conclusion: It is important for the ongoing care of people with intellectual and developmental disability that the value added by this nursing workforce not be overlooked as disability and health policies evolve. 
Implications for research, policy and practice: This cross sectional study lays the groundwork for further research about these Australian nurses, in particular more focussed research about the economic benefits of disability services employing nurses, description and effect of nursing interventions specific to people with intellectual and developmental disability, as well as theoretical work to conceptualise new, National Disability Insurance Scheme-ready, models of nursing care for people with intellectual and developmental disability.

What is already known about the topic?

- In the Australian context, little is known about the contemporary roles and practice of nurses who care for people with intellectual and developmental disability.

What this paper adds:

- This paper offers a detailed and modern insight into the roles and nursing practice of this marginalised group of nurses. Although all nurses offer physical nursing care, unique to these nurses is the breadth and depth of social, behavioural, emotional and adaptive behaviour support across the lifespan.

Keywords: intellectual disability; nursing; nurse; Australia; practice standards, care contexts

\section{INTRODUCTION}

The literature about Australian nurses who specialise in caring for people with intellectual and developmental disability (IDD) is limited in quantity and narrow in focus. ${ }^{1}$ This gap is historical, dating back to the commencement of the deinstitutionalisation era of the 1980 os when the role of nurses in the day-to-day lives of people with IDD was gradually phased out. ${ }^{2}$ That is, these nurses were marginalised while more socially-inclusive models were developed that did not mandate the need for nursing skills. ${ }^{2}$ Decades later, these nursing skills are still required as many remain employed in the IDD sector. ${ }^{3} \mathrm{~A}$ smaller number of nurses with expertise in the assessment of health and support needs of people with IDD also work in either primary or tertiary healthcare settings. ${ }^{4}$

The disparate healthcare needs and outcomes of many people with IDD requires varying degrees and frequency of care from nurses with specialised skills across multiple settings. ${ }^{5}$ However, we know very little about these nurses' roles, what constitutes their nursing practice and the type of contexts within which they work. In light of the new and rapidly evolving National Disability Insurance Scheme (NDIS), that promotes individualised support needs in the community, a deeper insight about the role of nurses in the care of those with IDD is vital. Understanding this role will provide a planning platform to embed nursing care within the NDIS framework, as a way of addressing inequities in health outcomes currently experienced by people with IDD.

\section{WHY ARE IDD NURSES NEEDED TO SUPPORT THE HEALTH OF PEOPLE WITH IDD?}

People with IDD represent approximately $3 \%$ of the Australian population, a prevalence shown to be fairly consistent over time, ${ }^{6}$ and generally experience poorer health, inequitable access to healthcare services and increased mortality relative to the general population.7 Further, their health needs are perhaps best understood as complex, chronic and lifelong. To illustrate, people with IDD are: at greater risk of exhibiting challenging behaviour and of developing mental health problems; experience increased rates of polypharmacy administration; and have multiple concurrent health conditions. ${ }^{8}$ Health needs and healthcare access represent a significant problem across Australia for this population, exacerbated by multiple individual and systemic barriers. ${ }^{9}$

\section{NURSES' ROLE WITHIN THE NDIS}

Under the NDIS, people with IDD can access services across a number of disciplines, through a variety of service providers, and delivered by workers with a diverse range of skills. ${ }^{10}$ Currently, the nurse's role in the NDIS appears vague and limited in nature. According to the National Disability Insurance Agency (NDIA), nurses may be required for the "provision of care, training and supervision of a delegated disability support worker to respond to the complex care needs of a participant where that care is not the usual responsibility of the health system". ${ }^{11(p .67)}$ That is, nursing care can only be claimed as a capacity-building support. The intended rationale for this limited scope for nursing care is to maximise client independence; wherein the nurse teaches the client or support worker healthcare skills and all other nursing services are provided by state and territory health departments. ${ }^{11}$ It is likely that many people with IDD and chronic and ongoing healthcare needs, cannot be met by the NDIS nurse training or consultation model. ${ }^{3}$ Equally, these healthcare needs are not best served by expensive and preventable hospital admissions. ${ }^{12}$

\section{WHAT DO THESE IDD NURSES DO?}

In the Australian context, little is known about where these nurses work, the types of roles for which they are employed, and the range of skills used in their practice. Insight is offered from the UK and Ireland where the role of specialist learning disability nurse is recognised. ${ }^{13}$ Australia has a general nursing 
register for newly qualified nurses; if a nurse does become employed within an IDD service, they may become experts in their chosen field, but remain professionally invisible. ${ }^{14}$ By contrast, many UK and Irish nurses are employed within acute hospital contexts as liaison nurses, ${ }^{15}$ forensic settings, ${ }^{16}$ as well as within community nursing teams. ${ }^{17}$ Specialisation within the nurses' role has also emerged in the areas of endof-life care, epilepsy management, challenging behaviour and early onset dementia. The most common activities for the community IDD nurse in the UK are health promotion, health surveillance, facilitating access to healthcare, health prevention, health education, and healthcare delivery. ${ }^{17}$

Australian nurses are primarily employed within IDD services with a small number employed within state-based specialist health units. The only current data available for this workforce does not report its total size - without a dedicated IDD health workforce category under the annual Australian Health Practitioner Regulation Agency (AHPRA) registration process these data are missing - but suggests that they are mainly older ( mean age $=52.31$ years ) and female, but male nurses were significantly older than female nurses. ${ }^{18}$ There is currently little appreciation for the complex, multi-faceted aspects of the nurse's role which previous research has shown extends to behaviour support, physical and mental health, sexuality education, intensive case management and complex inter-sectorial collaboration. ${ }^{4}$ Although Irish research has emphasised the physical and technical roles, ${ }^{19}$ the equivalent role in Australia also suggests psycho-social and relational emphases. Wilson et al. have proposed a preliminary model titled nurse-led, relationship-centred care reflecting the vital relational component of the nurse's role and represents a starting point in building a body of evidence. ${ }^{4}$ Missing from the evidence, is a comprehensive understanding of the roles, everyday practice, and context of IDD nursing; this paper seeks to fill this gap in our knowledge.

\section{AIMS}

To examine the role of nurses who care for people with IDD with respect to:

1) the range of primary roles fulfilled across this nursing workforce,

2) the context of the work setting; and

3) the breadth of their nursing practice.

\section{METHOD}

\section{DESIGN}

This study used an observational research design using descriptive survey tool with a cross-sectional, national sample.

\section{ETHICAL CONSIDERATIONS}

This study was approved by the Western Sydney University Human Research Ethics Committee (Approval ID: H12836).

\section{SURVEY DEVELOPMENT}

The survey was developed and piloted in 2018; the first version comprised five components:

1) Personal care (covering seven broad categories, each with between 3-5 sub-items listing type of care provided: physical healthcare, adaptive behaviour, managing problem behaviour, supporting mental illness, supporting spirituality, identity and body image, nursing assessment and intervention)

2) People with IDD cared for (three items: age range, gender, and living situation)

3) Professional contributions (three items: supervision/ development of support workers, development goals of the service, development within the field of IDD nursing)

4) Demographic data (12 items, including: age, gender, years' experience as a nurse, and highest qualifications)

5) Professional practice (Two items: nursing assessments and nursing interventions used).

The survey was assessed for content validity by experts, field-tested for clarity of language and appropriateness of items, and a test-retest reliability check reported an 83\% agreement. A pilot study using a convenience sample yielded 18 completed surveys. Following this, minor edits were made to some language, sections were shortened, a new section was added to Part One about interagency collaborations (two items: health and social agencies), and a new Part Six about nursing research (one item: level of participation in research) was included. A copy of the final survey is available from the corresponding authors.

\section{PARTICIPANTS}

The inclusion criteria were any nurses registered with AHPRA whose primary role was working with people with IDD. In the absence of any national sample frame, we adopted a purposive sampling approach using the publicly available database of all NDIS-registered Australian disability service providers. ${ }^{20}$ The databases were organised by state or territory, and by service category; there were 37 service categories in total with 70,646 registered service providers listed. A strategy was developed to delete wherever possible any non-nursing and non-IDD related providers, using the NDIA definitions of registration groups and providers. ${ }^{21}$

A consensus was reached about which registration groups were less likely to employ nurses. For instance, the group Assistance with Travel/Transport Arrangements was eliminated. Unrelated entries by non-nursing and non-IDD key terms such as psych, speech pathology, dementia and spinal injury were removed. As many NDIS providers offer a national service, all duplicate entries across state/territory databases were deleted. The building of a registered service provider list that met the needs of this study was an iterative approach; Figure 1 illustrates the steps undertaken and the service provider figures at each stage; the final list of registered service providers contacted was $N=4,741$. 


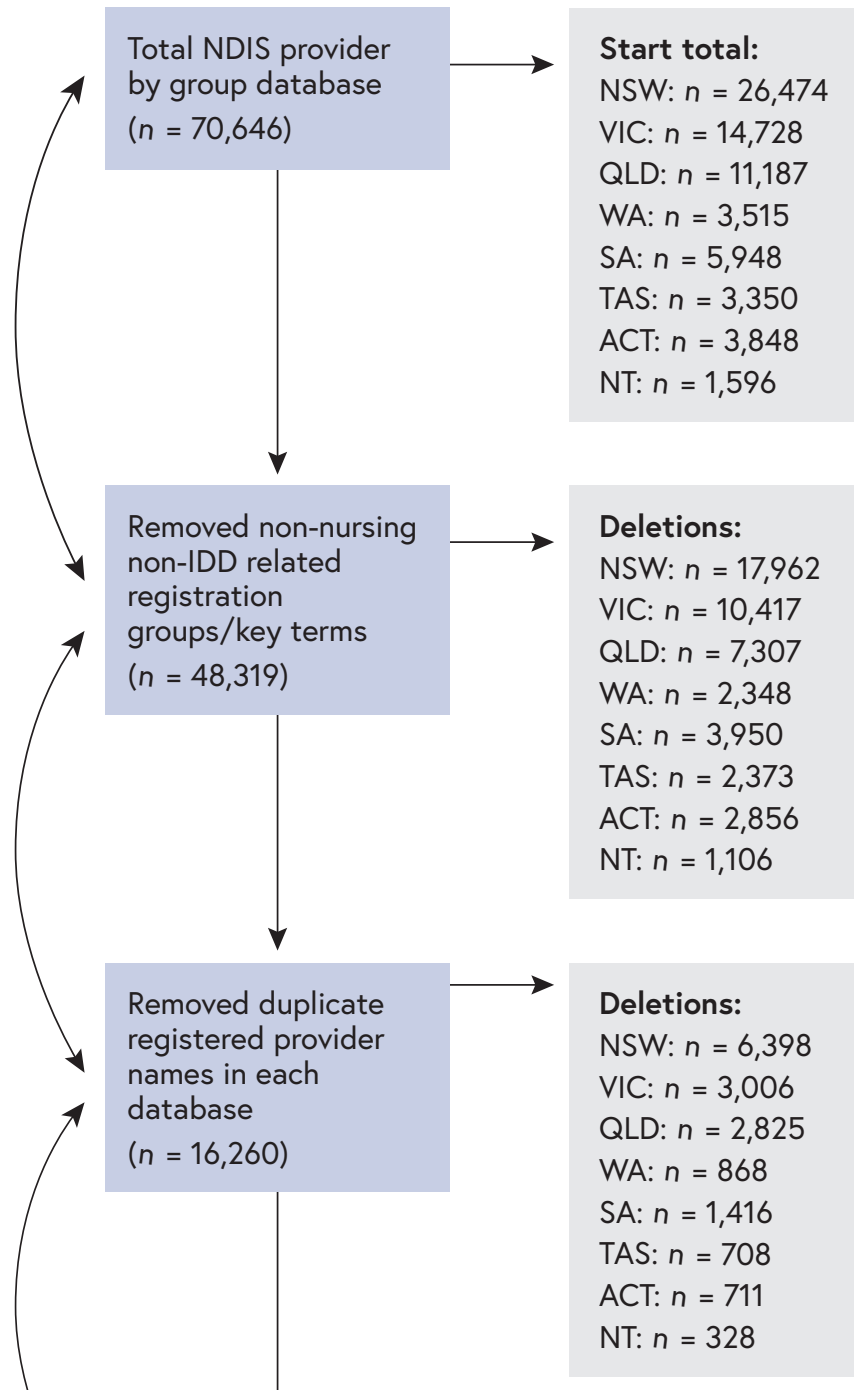

Removed duplicates across states/territory $(n=1,326)$

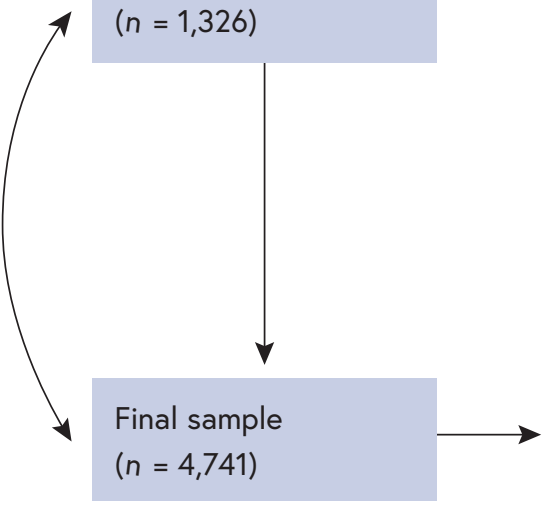

$(n=4,741)$
Start total:

NSW: $n=26,474$

QLD: $n=11,187$

WA: $n=3,515$

SA: $n=5,948$

TAS: $n=3,350$

ACT: $n=3,848$

NT: $n=1,596$

\section{Deletions:}

NS: $n=17,962$

VIC: $n=10,417$

QLD: $n=7,307$

WA: $n=2,348$

NSW: $n=6,398$

VIC: $n=3,006$

QLD: $n=2,825$

WA: $n=868$

SA: $n=1,416$

ACT: $n=71$

NT: $n=328$

\section{Deletions:}

NSW: $n=352$

VIC: $n=182$

QLD: $n=227$

WA: $n=74$

SA: $n=130$

TAS: $n=112$

ACT: $n=152$

NT: $n=97$

Remaining total:

NSW: $n=1,762$

VIC: $n=1,123$

QLD: $n=828$

WA: $n=225$

SA: $n=452$

TAS: $n=157$

ACT: $n=129$

NT: $n=65$

\section{DATA COLLECTION}

Survey data were collected using Qualtrics@ between September 2018 and January 2019. The provider database was divided among 10 research team members. Where possible, the list allocated matched the researcher's geographic location. Each researcher was given a telephone script; first, the researcher clarified whether the service employed any nurses. If the answer was affirmative and the service agreed, a flyer containing a hyperlink to the online survey was emailed to an agreed contact person who either forward the link to all nurses employed within the service or directly to nurses if their email address was provided. Emails with the flyer were also sent to those services who were not contactable by phone, with an invitation to forward the link to any nurses employed within the service. The survey was also advertised on nursing and IDD-related social media sites.

\section{DATA ANALYSIS}

IBM SPSS Statistics (Version 22) was used to analyse descriptive and inferential statistics, with appropriate Bonferroni adjustments made when required. ${ }^{22}$ Prior to analyses the dataset was screened for missing data, with no systematic missing data noted. ${ }^{22}$

\section{FINDINGS}

\section{RESPONSE AND DEMOGRAPHICS}

We received 162 responses, 59 of which were withheld due to incomplete data and two were removed as the respondents did not meet the inclusion criteria. This left a total sample of $\mathrm{N}=101$ respondents comprising 78 females (77\%), 22 males $(22 \%)$, and one undisclosed (0.01\%), with a mean age of 52.31 years $(S D=10.05)$. Responses by state and territory were: NSW $(n=70)$, Victoria $(n=14)$, South Australia $(n=6)$, Queensland $(n=5)$, the ACT $(n=2)$, Tasmania $(n=2)$, Western Australia $(n=1)$ and missing $(n=1)$. All respondents were registered with AHPRA: 88 registered, 11 endorsed enrolled, and 2 enrolled nurses.

\section{PRIMARY ROLES}

Descriptive statistics and sample frequencies were requested to explore the primary role focus among nurses as follows: 1) direct assessment and care of people with IDD, 2) supervision of support workers, 3) workforce management within a disability service, 4) education, 5) specialist consultation, and 6) systematic advocacy for people with an IDD. Respondents were asked to rate the role foci from the lowest (ie. one out of six) to the highest focus (ie. six out of six) of their role. Participants could give more than one focal category a particular rating. As an overall average, respondents rated direct assessment and care of people with IDD as the major focus of their role (4.61 out of a possible six), followed by supervision of support workers (4.59), education (4.32) and advocacy for those with 
an IDD (4.08). Specialist consultation (3.97) and workforce management (3.93) were the lowest rated areas of focus. When converted to the highest focus only (ie. six out of six), direct assessment and care of people with IDD was 42/101, and the lowest focus was specialist consultation at 18/101. Thus, 42 nurses reported that direct assessment and care was the highest focus of their role, and only 18 thought that specialist consultation was the highest focus of their role. When converted to lowest focus only, workforce management within a disability service was the highest $(n=9)$ compared to education $(n=1)$ meaning only one nurse thought education was the least important focus of their role.

\section{NURSING PRACTICE}

Nursing practice across the domains of 1) Physical healthcare, 2) Supporting adaptive behaviours, 3) Managing maladaptive/ challenging behaviours, 4) Managing mental illness, 5) Supporting spirituality, identity and body image, and 6) Use of formal assessment tools and the design of nursing interventions were explored.

Physical Healthcare. Physical healthcare was based on body systems similar to the widely-used Comprehensive Health Assessment Profile:23 respiratory, neurological/ sensory, gastrointestinal, musculoskeletal, integumentary, cardiovascular, endocrine, genitourinary and sexual health. Respondents $(N=101)$ reported they were most likely to provide support to meet needs related to the gastrointestinal system $(n=82)$ closely followed by support to meet needs related to neurological/sensory care $(n=81)$, whereas the provision of genitourinary care $(n=58)$ and sexual healthcare $(n=37)$ were much less frequent (see Table 1 for total sample responses). Gastrointestinal support and/or neurological/ sensory care may therefore reflect an area of greater and more regular care need for people with IDD.

TABLE 1: SAMPLE RESPONSES ( $N=597$ ) FOR PHYSICAL HEALTHCARE CATEGORIES

\begin{tabular}{|l|r|r|}
\hline Category & $\mathbf{n}$ & \% \\
\hline Sexual & 37 & 6.20 \\
\hline Respiratory & 74 & 12.40 \\
\hline Neurological & 81 & 13.57 \\
\hline Gastrointestinal & 82 & 13.74 \\
\hline Musculoskeletal & 76 & 12.73 \\
\hline Integumentary & 62 & 10.39 \\
\hline Cardiovascular & 61 & 10.22 \\
\hline Endocrine & 66 & 11.06 \\
\hline Genitourinary & 58 & 9.72 \\
\hline
\end{tabular}

To explore this in greater detail, nurses were asked to provide insight on specific examples of support within each category. For example, within the domain of musculoskeletal care, we surveyed whether hypotonic, hypertonic, or mobility support was more common. Across the nine aspects of physical healthcare we investigated, notable within-domain variation was only observed in two categories: neurological/ sensory care and musculoskeletal support. With respect to neurological care, nurses appeared more likely to provide support for seizure management $(n=74)$, conduct an assessment $(n=57)$ or provide sensory support $(n=52)$, but were less likely to provide support for neurodegenerative disease $(n=36)$. With respect to musculoskeletal care, nurses were more likely to provide support for mobility support ( $n$ $=66)$ than either hypotonic support $(n=34)$ or interventions for hypertonia $(n=38)$. See Table 2 for a detailed overview of within-domain differences.

TABLE 2: SAMPLE RESPONSES $(N=1118)$ FOR PHYSICAL HEALTHCARE SUB-CATEGORIES

\begin{tabular}{|c|c|c|}
\hline Category & $n$ & $\%$ \\
\hline Sexual & 48 & \\
\hline Sexual health support & 28 & 58.33 \\
\hline Sexual health management & 20 & 41.67 \\
\hline Respiratory & 212 & \\
\hline Respiratory Support & 48 & 22.64 \\
\hline Airway management & 43 & 20.28 \\
\hline Respiratory observations & 61 & 28.77 \\
\hline Manage chronic illness & 60 & 28.30 \\
\hline Gastrointestinal & 218 & \\
\hline Nutritional support & 71 & 32.57 \\
\hline Elimination management & 73 & 33.49 \\
\hline Manage chronic illness & 74 & 33.94 \\
\hline Integumentary & 207 & \\
\hline Integumentary support & 54 & 26.09 \\
\hline Integumentary management & 52 & 25.12 \\
\hline Integumentary observations & 53 & 25.60 \\
\hline Managing chronic illnesses & 48 & 23.19 \\
\hline Cardiovascular & 140 & \\
\hline Cardiovascular support & 49 & 35.00 \\
\hline Cardiovascular management & 46 & 32.86 \\
\hline Cardiovascular observations & 45 & 32.14 \\
\hline Endocrine & 156 & \\
\hline Endocrine support & 44 & 28.20 \\
\hline Endocrine management & 53 & 33.97 \\
\hline Endocrine observations & 59 & 37.82 \\
\hline Genitourinary & 137 & \\
\hline Genitourinary support & 50 & 36.50 \\
\hline Genitourinary management & 45 & 32.85 \\
\hline Genitourinary observations & 42 & 30.66 \\
\hline
\end{tabular}


Adaptive behaviour. This field contained five forced-choice categories (Yes/No) based on the Inventory for Client and Agency Planning (ICAP), ${ }^{24}$ a widely-used adaptive behaviour assessment tool for people with IDD. Categories were support for motor skills, social skills, communication, personal living skills and community living skills. Communication and social skills were the most commonly endorsed items ( $n=92$ and 86 respectively), followed by personal living ( $n=75)$, motor skills $(n=72)$, and community living $(n=69)$. Thus, nurses overwhelmingly offer support for people with IDD in this domain, with largely equivalent degrees across the range of adaptive behaviours.

Maladaptive/Challenging Behaviour. This domain included seven forced-choice behavioural items (Yes/No) based on the ICAP:24 self-harming, harmful, destructive, disruptive, unusual or repetitive, socially offensive, withdrawal or inattentive, and uncooperative behaviours. Self-harm and harmful to others were the most frequently provided forms of behavioural support ( $n=81$ and 8 o respectively). Management of destructive, disruptive, repetitive, and offensive behaviours was reported with a high degree of similarity ( $n=70,73,74,73$ respectively), while withdrawn/ inattentive behaviours were less frequent $(n=66)$. Hence, while nurses clearly offer widespread support for people with IDD in this domain, there may be some bias towards addressing self-harm and harm to others over other areas.

Mental health support. This item contained seven forced-choice items (Yes/No) that reflected the content of many mental health assessments: self-harm, anxiety, depression, eating disorder, psychosis and/or mania, suicidal ideation, and offering no mental health support. Nurses were most likely to provide support for anxiety $(n=79)$ and depression $(n=69)$ and least likely to provide support for suicidality $(n=25)$ or to offer no support at all $(n=19)$. Other areas related to the provision of support were assistance with self-harm $(n=55)$, symptoms of mania $(n=55)$ and eating disorders $(n=46)$. There may subsequently be a gap in the provision of support for suicidality as this is an uncommon issue.

Supporting spirituality, identity, and body image. Respondents were asked to indicate either yes or no as to whether they provided support for spirituality, identity and body image in their daily nursing practice. The responses indicated that while nurses provide relatively equivalent degrees of support across the spiritual ( $n=44)$, identity $(n=48)$ and body image $(n=39)$ domains, their support for these areas is generally lower than any other domain (eg. adaptive behaviour or maladaptive/challenging behaviour).

\section{INTER-AGENCY COLLABORATION}

Respondents were asked to list the six main health and social agencies they collaborated with. Responses were categorically organised and are summarised in Tables 3 and 4 . The most frequent health collaborations were allied health and medical consultations and the most frequent social agencies were with the NDIA and state-based trustee/ guardianship services.

TABLE 3: SAMPLE RESPONSES ( $N=506)$ FOR HEALTH INTER-AGENCY COLLABORATIONS

\begin{tabular}{lrr}
\hline Category & $\mathbf{n}$ & \% \\
\hline Allied health & 168 & 33.20 \\
\hline Specialist medical consultants & 143 & 28.26 \\
\hline GPs and other primary health & 98 & 19.37 \\
\hline Hospitals - in-patient & 57 & 11.26 \\
\hline Nurse specialists & 19 & 3.75 \\
\hline Health and outpatient clinics & 9 & 1.78 \\
\hline Other & 12 & 2.37 \\
\hline
\end{tabular}

TABLE 4: SAMPLE RESPONSES ( $N=312$ ) FOR SOCIAL INTER-AGENCY COLLABORATIONS

\begin{tabular}{lcr}
\hline Category & $\mathbf{n}$ & $\%$ \\
\hline National Disability Insurance Agency & 75 & 24.04 \\
\hline $\begin{array}{l}\text { State-based trustee and guardianship } \\
\text { agencies }\end{array}$ & 67 & 21.47 \\
\hline Disability service providers & 55 & 17.63 \\
\hline National Department of Human Services & 36 & 11.54 \\
\hline State-based disability and community & 32 & 10.26 \\
agencies & & \\
\hline Education providers & 23 & 7.37 \\
\hline State-based justice agencies & 5 & 1.60 \\
\hline Advocacy services & 5 & 1.60 \\
\hline State-based child protection agencies & 2 & 0.64 \\
\hline Out of home care service providers & 2 & 0.64 \\
\hline Aged care service providers & 2 & 0.64 \\
\hline Other & 8 & 2.56 \\
\hline
\end{tabular}

\section{PROFESSIONAL CONTRIBUTIONS}

Professional contributions covered the following options: 1) Develop and deliver education packages, 2) Develop practice guidelines/policies, 3) Supervision of other staff, 4) Contribute to other staff career development, and 5) Do not supervise or provide development of paid caregivers. Nurses were more likely to supervise other staff $(n=86)$, and as a natural consequence of that, unlikely not to be engaged in supervision or development of paid caregivers $(n=19)$. Developing and delivering education $(n=45)$, developing practice guidelines/policies $(n=39)$, and contributing to other staff career development $(n=46)$ were reported in similar degrees by nurses in this sample. Hence, nurses are most likely to be engaged in the supervision of others than any other aspect of their professional contribution. 


\section{RESEARCH PARTICIPATION}

To determine the extent to which nurses participated in IDD research, respondents were asked to respond to each of four statements: 1) do not research, 2) read and use research, 3) support others in conducting research, and 4) conduct research myself. Participant responses indicated that nurses were more likely to read and use research $(n=62)$, than they were to conduct research themselves $(n=7)$. The frequencies for not being involved in conducting research $(n=30)$ and supporting others in conducting their research $(n=29)$ were approximately even.

\section{OVERVIEW OF PEOPLE WITH IDD SUPPORTED AND CONTEXT OF SUPPORT}

Nurses were asked questions about the demographic profile of the people with IDD they work with. Consistent with expectations, most clients were aged $18-64(n=75)$, with relatively fewer children $(n=17)$ and/or older clients $(n=8)$. In terms of gender, eight respondents reported working only with females, 26 only with males, 64 with 50/50 male/female (two non-disclosed).

Respondents were asked to select from eight possible locations indicating their main area of practise: 1 ) aged care facility, 2) family home, 3) group home, 4) semi-independent living with staff support, 5) correctional or forensic setting, 6 ) independent living with home services, 7) independent living with informal unpaid carer support, and 8) high dependent living with staff intervention. Nurses were most likely to be working in a disability group home $(n=59)$ or in high-dependent living with staff intervention $(n=50)$, and unlikely to be working in a correctional/forensic setting $(n=8)$, aged care facility $(n=13)$, or independent living with informal unpaid support $(n=15)$.

\section{DISCUSSION}

This is the first study to survey Australian nurses whose primary role is to care for people with IDD. The findings extend previous work which offers a field-specific preliminary nurse-led, relationship-centred model of care. ${ }^{1,4}$ In particular, the number and range of health and social service collaborations that nurses interact with exemplify the extent of the relationship-centred model of care provided. Nursing practice, although centred on physical health needs, covers a range of domains that make this speciality area of nursing practice unique. That is, few, if any, other nursing specialties cover a breadth of practice involving physical care, support for adaptive behaviour skills, responding to challenging behaviours, support for mental health, and spirituality, identity and body image across the lifespan and across multiple contexts. This has implications for nurses and for the people in their care. Nurses need instruction and experience in a wide range of social and clinical fields in order to integrate effective care with a uniquely relational approach. People with intellectual disability receiving the care of nurses need to be assured that the physical and social care that they receive is of high quality across a broad range of needs and life experiences, and that this outcome is best achieved in the context of a relationship-centred model. 4

As far as we are aware, there is only one other published study using a descriptive survey tool to explore the role of the nurse working with people with IDD. ${ }^{25}$ Based on an analysis of 26 responses, the frequency of skills such as personal hygiene, medication administration, and mouth care are undertaken more than once per day, whereas skills such as urinary catheterisation and violence prevention were used monthly. Although these data have helped build the evidence-base, ${ }^{2}$ our survey data offers significantly greater breadth and depth, and also represents a strong and contextually unique evidence-base for further research. The range of nursing roles fulfilled and the breadth of nursing practice described reflects the known complexity of health and social care needs associated with people with IDD, in particular the critical issues related to chronicity and polypharmacy. ${ }^{3}$ This picture is also likely to reflect the growing recognition that with an ever increasing life expectancy, people with IDD are experiencing age-related health problems, chronic conditions and often multi-morbidity. 3,5 The future of nursing care for people with IDD will therefore rely on the adaptability of individual nurses to apply the skills already developed while working in the field of IDD and expanded to meet the needs of people with IDD into old age. This process of adaptation has been ongoing for many years as the population of people with IDD grows and their life expectancy lengthens.

The evidence around the ability of people with IDD to engage with services and access healthcare systems alongside increasing levels of multi-morbidity and the lack of knowledge and coordination in healthcare service highlights the value of the breadth of skills and range of roles of nurses who work with people with IDD. The ability to provide direct care across the domains of physical and mental health within the group home context, was complemented by their role in coordinating services and providing support and education to other health professionals for participants in this survey. That these skills appear to have been overlooked or undervalued by the NDIS policy framework is, in our view, an anomaly. ${ }^{11}$ These are critical nursing skills that could also be implemented beyond the NDIS, within health-system based liaison roles, such as in the UK and Ireland, ${ }^{15}$ to help counter avoidable deaths in acute hospital settings. The limited amount of active research being undertaken by these nurses does present a major role limitation, in particular for nurses working in more advanced roles as this is required to build the evidence base. 


\section{LIMITATIONS}

Inconsistent responses across geographical areas of Australia limits the generalisability of the findings across the national nursing workforce. The healthcare needs of people with IDD are not limited by geographical distribution, and therefore, combined with a response rate of $\mathrm{N}=101$, we propose that the findings represent a reasonably confident summary of nurses' roles, practices and contexts when caring for people with IDD. We acknowledge that the iterative method used to build an NDIS registered service provider list for recruitment may have meant the exclusion of some prospective respondents. Further, we acknowledge that the nature of descriptive studies using a cross-sectional design, while offering breadth to data collection, often means that the granularity of data, and therefore interpretation, may be limited.

\section{CONCLUSION}

Nurses working with people with IDD demonstrate a breadth and depth of practice reflective of the diverse needs of people with IDD and the diverse roles played by the nurses. In light of the evidence around poorer health outcomes of people with IDD and the growing need for preventative healthcare amongst an ageing IDD population, demand will grow for the inclusion of nurses in the care of people with IDD. However, we are facing the dual issues of an ageing and increasingly invisible workforce. It is vital that we do not overlook the value of the IDD workforce nor erode their role as policy in the IDD space evolves.

\section{IMPLICATIONS FOR RESEARCH, POLICY AND PRACTICE}

This cross-sectional study provides a basis upon which further research about the contribution made by these Australian nurses can progress. In particular, more focussed research about the economic benefits of disability services employing nurses and description and effect of nursing interventions specific to people with intellectual and developmental disability is required. Just as importantly, theoretical work to conceptualise new, National Disability Insurance Scheme-ready models of nursing care for people with intellectual and developmental disability is needed in order for this sector of the nursing profession to develop and advance. Extant models of specialist practice such as those in operation in the UK and Ireland could combine with models of nursing care designed and implemented in the Australian contexts in order to serve the needs and support the abilities of Australians with IDD. The results of this study indicate that any such models would have to combine recognition of nurses' skills in delivering direct care to people with IDD with their capacity to develop lasting therapeutic relationships with those for whom they care.
Acknowledgements: We would like to acknowledge the nurses who supported the development and piloting of the survey tool and those who took the time to complete this online survey. We also acknowledge the input of Suzanne Robinson and Irene Rogers, from Edith Cowan and Central Queensland Universities respectively, who worked as research assistants on the project.

Funding Support: This research was funded by a research grant from the Professional Association of Nurses in Developmental Disabilities Australia (PANDDA), Inc. The views herein are those of the authors and do not necessarily reflect the views of PANDDA.

Declaration of conflicting interests: Nathan Wilson was elected as PANDDA President after this project was awarded and contracted by PANDDA. Virginia Howie is a current member of the PANDDA Executive Committee. No author has any other conflicts to declare.

\section{REFERENCES}

1. Jaques $\mathrm{H}$, Lewis $\mathrm{P}$, Wiese M, O'Reilly K, Wilson NJ Understanding the contemporary role of the intellectual disability nurse: A review of the literature. J Clin Nurs; 2018; 27(21-22): 3858-3871. http://dx.doi.org/10.1111/jocn.14555

2. O'Reilly K, Lewis P, Wiese M, et al. An exploration of the practice, policy and legislative issues of the specialist area of nursing people with intellectual disability: A scoping review. Nurs Inq; 2018; 25(4): e12258. https://doi.org/10.1111/nin.12258

3. Wilson NJ, Riches VC, Riches T, Durvasula S, Rodrigues R, Pinto S. Complex support needs profile of an adult cohort with intellectual disability transitioning from state-based service provision to NDIS-funded residential support. J Intell Dev Disabil; 2020. https://doi.org/10.3109/13668250.2020.1717069

4. Wilson NJ, Wiese M, Lewis P, Jaques H, O'Reilly K. Nurses working in intellectual disability-specific settings talk about the uniqueness of their role: A qualitative study. J Adv Nurs; 2019; 75(4): 812-822. https://doi.org/10.1111/jan.13898

5. Wilson NJ, Charnock D. Developmental and intellectual disability. In Living with Chronic Illness and Disability: Principles for nursing practice, edited by E. Chang \& A. Johnson, 3rd ed. 129-145. Elsevier: Sydney, Australia. 2017.

6. Australian Institute of Health and Welfare. Disability in Australia: Intellectual Disability: Bulletin 67, November, 2008 Australian Institute of Health and Welfare: Canberra. https://www.aihw.gov.au/getmedia/5a1b2a34-78bb-4696a975-3121658a9505/bulletin67.pdf.aspx?inline=true (accessed 08.01.18)

7. Florio T, Trollor J. Mortality among a cohort of persons with an intellectual disability in New South Wales, Australia. J App Res Intell Disabil; 2015; 28(5): 383-393. http://dx.doi.org/10.1111/ jar.12190

8. Cooper SA, Smiley E, Morrison J, Williamson A, Allan L. Mental ill-health in adults with intellectual disabilities: Prevalence and associated factors. Brit J Psych; 2007; 190(1): 27-35. https://doi.org/10.1192/bjp.bp.106.022483

9. Whittle EL, Fisher K, Reppermund S, Trollor J. Access to mental health services: The experiences of people with intellectual disabilities. J App Res Intell Disabil; 2019; 32: 368-379. https://doi.org/10.1111/jar.12533 
10. Dowse L, Wiese M, Smith L. Workforce issues in the Australian National Disability Insurance Scheme: Complex support needs ready? Res Pract Intell Devel Disabil; 2016; 3(1): 54-64. https://doi.org/10.1080/23297018.2016.1161542

11. National Disability Insurance Agency. NDIS Price Guide NSW Qld Vic Tas. 2019. https://www.ndis.gov.au/providers/priceguides-and-information

12. Hosking FJ, Carey IM, DeWilde S, Harris T, Beighton C, Cook DG. Preventable emergency hospital admissions among adults with intellectual disability in England. Ann Fam Med. 2017; 15(5): 462-470. https://doi.org/10.1370/afm.2104.

13. Sweeney J, Mitchell D. A challenge to nursing: An historical review of intellectual disability nursing in the UK and Ireland. J Clin Nurs. 2009; 18(19): 2754-2763. https://doi.org/10.1111/j.1365-2702.2009.02889.x

14. Wilson NJ, Lewis P, O'Reilly K, et al. Reframing the role, identity and standards for practice for registered nurses working in the specialty area of intellectual and developmental disability in Australia: The NDIS and beyond. Collegian; 2019; 26(1): 132-139. https://doi.org/10.1016/j.colegn.2018.06.002

15. MacArthur J, Brown M, McKechanie A, Mack S, Hayes M, Fletcher J. Making reasonable and achievable adjustments: The contributions of learning disability liaison nurses in 'getting it right' for people with learning disabilities receiving general hospital care. J Adv Nurs; 2015; 71(7): 1552-1563. https://doi.org/10.1111/jan.12629

16. Mason T, Phipps D. Forensic learning disability nursing skills and competencies: A study of forensic and non-forensic nurses. Iss Ment Health Nurs; 2010; 31(11): 708-715. https://doi.org/10.3109/01612840.2010.500793

17. Mafuba K, Gates B. An investigation into the public health roles of community learning disability nurses. Brit J Learn Disabil; 2015; 43(1): 1-7. https://doi.org/10.1111/bld.12071

18. Lewis P, Collison J, Whitehead L, et al. Demographic profile of the intellectual disability nursing workforce in Australia: Findings from a national survey. J Intell Dev Disabil; 2020. https://doi.org/10.3109/13668250.2019.1685478

19. Sheerin FK, McConky R. Frontline care in Irish intellectual disability services. J Intell Disabil; 2008; 12(2):127-141. https://doi.org/10.1177/17444629508090984

20. National Disability Insurance Agency. Find a registered provider. https://www.ndis.gov.au/participants/working-providers/findregistered-provider. 2018a (accessed 30.07.2018).

21. National Disability Insurance Agency. 2018b. Provider Registration Guide to Suitability. 2018b. https://providertoolkit.ndis.gov.au/26-key-registrationrequirements (accessed 30.07.2018).

22. Hills AM. Foolproof guide to statistics using IBM SPSS (2nd edn). Pearson Education: Australia. 2011.

23. Lennox N, Bain C, Rey-Conde T, Purdie D, Bush R, Pandeya N Effects of a comprehensive health assessment programme for Australian adults with intellectual disability: A cluster randomized trial. Int J Epidem; 2007; 36(1): 139-146. https://doi.org/10.1093/ije/dyl254

24. Bruininks RH, Hill BK, Weatherman RF, Woodcock RW. Inventory for client agency and planning. Riverside Publishing: Chicago, Ilinois. 1986.

25. McKeon M. A survey of clinical nursing skills in intellectual disability nursing. J Intell Disabil; 2009; 13(1): 31-41. 